\title{
"Parceiros" assimétricos: trabalho e saúde de motoristas por aplicativos no Rio de Janeiro, Brasil
}

\author{
Asymmetric "partners": work and health of app drivers \\ in Rio de Janeiro, Brazil
}

Letícia Pessoa Masson (https://orcid.org/0000-0002-5422-286X) ${ }^{1}$

Denise Alvarez (https://orcid.org/0000-0002-3216-3993) ${ }^{2}$

Simone Oliveira (https://orcid.org/0000-0002-1477-749X) ${ }^{1}$

Márcia Teixeira (https://orcid.org/0000-0002-9502-0789) ${ }^{1}$

Samara Leal (https://orcid.org/0000-0003-1890-1985) ${ }^{3}$

Gabriela Siqueira Salomão (https://orcid.org/0000-0001-7251-8149) ${ }^{4}$

Sarah de Paulo do Amaral (https://orcid.org/0000-0002-5221-6685) ${ }^{4}$

Cirlene de Souza Christo (https://orcid.org/0000-0001-8148-9730) ${ }^{4}$

${ }^{1}$ Centro de Estudos da Saúde do Trabalhador e Ecologia Humana, Escola Nacional de Saúde Pública Sergio Arouca, Fundação Oswaldo Cruz. R. Leopoldo Bulhões 1480, Manguinhos. 21041-210 Rio de Janeiro RJ Brasil.leticiamasson@ ensp.fiocruz.br

${ }^{2}$ Programa de Pós-

Graduação em Engenharia de Produção, Universidade

Federal Fluminense. Niterói RJ Brasil.

${ }^{3}$ Programa de PósGraduação em Saúde Pública, Escola Nacional de Saúde Pública Sergio Arouca, Fundação Oswaldo Cruz. Rio de Janeiro RJ Brasil.

${ }^{4}$ Instituto de Psicologia, Universidade Federal do Rio de Janeiro. Rio de Janeiro RJ Brasil.

\begin{abstract}
This paper is the product of an ongoing research's preliminary results with app drivers and aims to discuss how the game of forces has occurred in the relationships established between companies, workers, regulatory bodies, and society. This exploratory qualitative study employed document analysis, a questionnaire, and semi-structured interviews with drivers linked to associations in Rio de Janeiro (RJ), Brazil. The analysis was conducted from a tripolar perspective based on the theoretical-methodological framework of Ergology and social life's micro and macroscopic spaces, encompassing the poles referring to human activity, the market, and politics. The results show a background of norms built on this work about the relationship with companies, passengers, and the drivers themselves, besides issues raised from the COVID-19 pandemic. We can conclude that it is necessary not to counteract technological evolution to achieve workers' rights and health. We should recall that no action aimed at ensuring the reconciliation of health, work, and rights will advance without relying on a fruitful and balanced trend between the three poles mentioned.
\end{abstract}

Key words App drivers, Occupational Health, Uberization, Ergology
Resumo Este artigo é fruto de resultados preliminares de uma pesquisa em andamento com motoristas por aplicativo e tem por objetivo discutir sobre como tem se dado o jogo de forças nas relações que se estabelecem entre as empresas, os trabalhadores, os órgãos reguladores e a sociedade. $O$ estudo exploratório, com abordagem qualitativa, utilizou análise documental, questionário e entrevistas semiestruturadas com motoristas ligados a associações do Rio de Janeiro/RJ. Tendo como base o referencial teórico-metodológico da Ergologia, e a partir dos espaços micro e macroscópico da vida social, a análise se deu em uma perspectiva tripolar, abarcando os polos referentes à atividade humana, ao mercado e à política. Os resultados apresentam normas antecedentes que vêm sendo construídas sobre este trabalho na relação com as empresas, com os passageiros e entre os próprios motoristas, além de questões trazidas a partir da pandemia de COVID-19. Conclui-se ser necessário não contrapor a evolução tecnológica à conquista de direitos e da saúde dos trabalhadores, sendo imperativo lembrar que nenhuma ação que vise garantir a conciliação entre saúde, trabalho e direitos conseguirá avançar sem contar com uma dinâmica frutífera, e tendencialmente equilibra$d a$, entre os três polos mencionados.

Palavras-chave Motoristas por aplicativo, Saúde do trabalhador, Uberização, Ergologia 


\section{Introdução}

Nos últimos anos, tecnologias da microeletrônica vêm estendendo sua capacidade de uso e gerenciamento de dados para conectar consumidores e prestadores de serviço a custos cada vez mais baixos, superando, em alguns casos, performances de grandes conglomerados já estabelecidos ${ }^{1}$. Empresas-plataforma como Uber e Airbnb, sem deter patrimônio material significativo, constituíram-se vertiginosamente em valiosos gigantes corporativos. Tendo como base argumentos calcados em uma suposta economia do compartilhamento, evidenciam-se práticas que corroboram e ampliam processos alarmantes de precarização do trabalho e deterioração de direitos trabalhis$\operatorname{tas}^{1 ; 2}$. Sustentadas por mecanismos de coordenação algorítmica, as empresas propõem sincronizar interesses de distintos grupos (consumidores, produtores, provedores etc.) por elas considerados independentes ${ }^{3}$.

Para $\mathrm{Abílio}^{4}$, a uberização seria uma nova forma de controle, gerenciamento e organização do trabalho operada de maneira dissimulada a partir de um gerenciamento algorítmico, e se caracterizaria por quatro elementos centrais: 1. a concepção do trabalhador just-in-time, sem garantias (legais, contratuais); 2. a apresentação das empresas como mediadoras e não como contratantes; 3. a passagem de um contingente predefinido de trabalhadores para a figura de uma multidão de trabalhadores disponíveis; e 4. o deslizamento da identidade profissional do trabalho para a de trabalho amador.

Essa nova configuração de organização e gerenciamento do trabalho traz importantes consequências, tanto sobre os elementos que definem uma relação de subordinação jurídica de emprego, como sobre o processo de apropriação da energia humana e dos custos que ele comporta para as pessoas. Convoca, ainda, importantes indagações sobre a relação trabalho e saúde, nas quais se destacam a atuação de motoristas por aplicativos, com impactos também nas questões de mobilidade urbana em todo o mundo ${ }^{3}$.

No Brasil essa atividade está em crescimento exponencial. A Uber, maior empresa neste segmento, conta com três milhões de motoristas, sendo seiscentos mil no Brasil, nos últimos seis anos $^{5}$. Importante ressaltar que, em um momento de forte crise econômica e política, com altos índices de desemprego e informalização do trabalho, a chegada e a expansão vertiginosa dessas empresas-plataforma encontraram terreno fértil no país, cenário agravado com a pandemia de COVID-19.
Vejamos como a Uber ${ }^{6}$ se define em seu site na internet: uma empresa de tecnologia que cria oportunidades ao colocar o mundo em movimento. Encaramos os desafios mais complexos para ajudar nossos parceiros e usuários a se locomover usando uma plataforma integrada de mobilidade presente em mais de 10 mil cidades do planeta.

$\mathrm{O}$ emprego do termo parceiro em sua autodescrição tem um propósito: acobertar uma relação de trabalho. Essa denominação compõe a construção de uma narrativa de suposta autonomia e flexibilidade usada pela empresa para o não reconhecimento dessa relação, buscando assim isentar-se da responsabilidade de cumprir seus deveres trabalhistas, a partir da ideia de uma horizontalidade entre motorista e empresa. Sua forma de atuação alia um discurso de liberdade a um alto nível de controle das condutas dos trabalhadores, feito por programação ${ }^{7}$. Apesar da promessa feita aos trabalhadores sobre serem livres para definir quando, onde e como trabalhar, a adesão a essa lógica tem representado uma subordinação real dos trabalhadores a regras e comandos gerenciais, que é qualificada por $\mathrm{Su}$ piot $^{8}$ como uma liberdade programada ou uma autonomia na subordinação. Diferentemente do sistema taylorista, já que viabilizado por um monitoramento, comando e controle algorítmico do trabalho, esse gerenciamento se efetiva sem a necessidade de ordem direta.

Indagamo-nos sobre esse cenário e sua relação com a saúde dos trabalhadores a partir dos espaços micro e macroscópico da vida social, os quais se interpenetram em uma perspectiva tripolar ${ }^{9}$. Schwartz ${ }^{9}$ identifica três polos presentes nas sociedades democráticas e regidas pelo arcabouço do Direito: o polo da gestão (ou ergológico) e do debate de normas, referente à atividade humana; o polo mercantil, onde atuam os valores quantitativos e dimensionados do mercado; e o polo do político, ou da cidadania, referente aos valores do viver em comum. Esse olhar ergológico ${ }^{10}$ identifica na atividade de trabalho um permanente debate de normas entre normas antecedentes e renormatizações.

A atividade de trabalho é indiferente ao grande proprietário, que se distancia da realidade vivida pelos trabalhadores, ignorando suas condições de vida, assegurando-se um custo quase zero para a maquinaria, a matéria-prima (combustíveis, reparos, renovação de frota) e a própria força de trabalho ${ }^{11}$. E, é importante apontar que, não apenas a empresa-plataforma (polo mercantil), mas também o poder público (polo do político), muitas vezes desconhece e/ou desconsidera 
a dimensão ergológica presente na atividade do motorista (polo da gestão) ${ }^{9}$.

Neste sentido, apresentamos algumas questões norteadoras: que inflexões e jogos de força estão presentes nesse cenário face ao espaço tripolar apresentado por Schwartz ${ }^{9}$ ? Como se organizam as atividades dos trabalhadores, quais as normas antecedentes aí presentes? Como se conforma a dimensão coletiva deste trabalho, que entidades coletivas relativamente pertinentes ${ }^{9}$ aí se esboçam? Quais as perspectivas da construção de reservas de alternativas ${ }^{12}$ ?

Acredita-se que tais questões contribuem para problematizar o modo de relação e organização do trabalho adotado por empresas-plataforma no agenciamento do trabalho de motoristas que atuam por aplicativos e sua relação com a saúde destes trabalhadores. Saúde, por sua vez, compreendida como capacidade de recriação das normas frente ao meio em que se vive e trabalha ${ }^{13}$. Assim, este texto tem como objetivo discutir sobre como tem se dado o jogo de forças nas relações que se estabelecem entre as empresas, os trabalhadores, os órgãos reguladores e a sociedade.

\section{Abordagem teórico-metodológica}

Para a perspectiva ergológica ${ }^{10}$, a atividade representa uma dinâmica de contradições potenciais, sendo lugar de debates entre normas antecedentes e tendências a renormatizações. Isso se dá em função das variabilidades e acontecimentos do meio físico e social humano, o que Canguilhem denomina infidelidades do meio, assim como da singularidade das pessoas e das situações. Estas infidelidades são geridas permanentemente levando-se em consideração as normas antecedentes e suas possibilidades de renormatizações. Tais renormatizações, resultado de microescolhas feitas no curso da atividade de trabalho, podem até mesmo produzir novas técnicas e saberes que, quiçá, serão incorporados/patrimonializados às normas antecedentes ${ }^{10}$. Assim, debates de normas, imersos em um mundo em que circulam valores diversos, podem conduzir à construção de reservas de alternativas ${ }^{12}$, ao instaurar outros modos de se viver em conjunto, visando garantir o bem viver coletivo. E, nesta perspectiva, há construção de saúde, na medida em que ela significa a capacidade de modificar o meio em que se vive e trabalha, através da instauração de novas normas $^{13}$.

Esta dinâmica de reconstrução permanente do que ocorre na atividade, em nossas socieda- des regidas por leis, vai ser balizada pela tentativa de equilíbrio entre os três polos evocados por Schwartz ${ }^{9}$. No polo da gestão, haverá a tentativa permanente de gerenciar os debates e solicitações pertinentes à atividade, com suas dúvidas, impasses e evocação de diferentes valores. No polo mercantil, a volatilidade e as pressões regidas pelos interesses financeiros quantitativos do mercado impõem sua racionalidade. Aqui o jogo de interesses das empresas e grupos econômicos pressiona permanentemente em busca de resultados. E finalmente, no polo do político, ou da cidadania, os valores do bem comum são evocados com suas diferentes visões do que isto poderia significar. Há que se dimensionar recursos e contemplar direitos, respondendo à permanente pressão dos demais polos.

Foi este cenário teórico, que evoca tensões e necessidade de negociações em diferentes níveis, que buscamos entender na realidade estudada.

A pesquisa, que possui caráter qualitativo e participativo, vem realizando:

- Levantamento bibliográfico e documental, a fim de acompanhar: a produção de literatura sobre o tema, matérias jornalísticas, termos de uso das empresas e o que tem sido feito no âmbito legislativo, além de discussões de grupos de trabalhadores em redes sociais (Youtube, Instagram e Facebook).

- Conversas com interlocutores-chaves (presidentes de duas associações de motoristas no estado do Rio de Janeiro) sobre o trabalho, o funcionamento e composição das associações, as reivindicações desses trabalhadores; e

- Aplicação de um questionário que tinha por objetivo levantar questões iniciais sobre os motoristas a serem aprofundadas em grupos de discussão que viriam a ocorrer em fase posterior da pesquisa, além de ser um meio de convidá-los para esta etapa. O questionário, on-line, continha 26 questões nas quais buscou-se levantar as características sociodemográficas dos trabalhadores, alguns aspectos gerais do seu trabalho e sua relação com a saúde, além da satisfação com a atividade e condições de trabalho. Embora sua aplicação não fosse restrita a um grupo específico de motoristas, a grande maioria do total de 29 respondentes era de motoristas ligados às associações já mencionadas.

- Participação em um encontro organizado por associações de motoristas por aplicativos do Rio de Janeiro, em novembro de 2019. O evento visava à confraternização entre estes trabalhadores e o fortalecimento da categoria. $\mathrm{Na}$ ocasião, apresentamos o projeto, conversamos com vários 
motoristas e disponibilizamos computadores para preenchimento do questionário.

O projeto foi aprovado pelo Comitê de Ética em Pesquisa da ENSP/Fiocruz e todas as falas aqui citadas foram apresentadas sem a identificação dos participantes.

\section{Resultados e discussão}

\section{Regulação do trabalho}

As mudanças advindas das empresas-plataforma para as relações entre trabalhador e empresa geram demandas para os governos, seja na regulação de política econômica e urbana, seja por ações de proteção aos trabalhadores ou de questionamentos, via justiça do trabalho, quanto ao reconhecimento de vínculo e demais direitos dele decorrentes. Nesse âmbito, tem havido debate intenso entre os três polos enunciados por Schwartz': o polo ergológico pressiona o polo do político que, por sua vez, é pressionado pelo polo mercantil. Essa dinâmica funciona em todas as direções dos polos, com pesos diversos e assimétricos.

As chamadas normas antecedentes ${ }^{12}$ exprimem ideais, regras, objetivos, modelos vindos de instâncias exteriores ao indivíduo sendo, portanto, heterodeterminadas. Ao trabalhar, utilizamos manuais e notas técnicas, regras de gestão, instruções, procedimentos, regramentos legais etc que, ao mesmo tempo, nos constrangem e nos permitem desenvolver uma atividade singular e renormatizada. No Brasil, empresas-plataforma resistem com sucesso à regulação dos mercados, a instrumentos normativos de políticas públicas e à legislação trabalhista. De modo que as normas criadas pelas empresas tendem a prevalecer, ao não serem reguladas pela legislação. Assim, o dimensionamento do político em favor do polo da atividade torna-se fragilizado. $\mathrm{O}$ movimento de criação e discussão de tais normas está em vigor nos últimos anos, como se pode verificar no Quadro 1.

O debate legal no país (polo do político) tem sido direcionado mais para questões de mobilidade urbana do que sobre a relação/exploração do trabalho no âmbito do direito trabalhista. O trabalho de motoristas por aplicativo tem sido regulamentado no marco da política de mobilidade urbana (Lei 12.587/2012) e regulamentado nacionalmente por meio da Lei Federal 13.640/2018. A regulação federal organiza a oferta do serviço de transporte remunerado privado individual de passageiros e delega aos municípios a competência de regulá-lo e fiscalizá-lo. Estabelece que somente será autorizado à prática de tal serviço o motorista que for contribuinte individual do Instituto Nacional do Seguro Social (INSS) exercendo atividade econômica de natureza urbana, com fins lucrativos ou não ${ }^{14}$.

As normas proíbem a exclusividade para uso da plataforma, o que possibilita aos motoristas a atuação simultânea em várias plataformas. Segundo Frazão ${ }^{15}$, a legislação federal não explora as características materiais da 'parceria' nem o que a distinguiria, do ponto de vista fático, da relação de trabalho subordinado (p. 321).

$\mathrm{Na}$ esfera do direito trabalhista no Brasil, o debate gira em torno da natureza da relação entre os motoristas e as empresas de aplicativos. Assim, ainda não existe jurisprudência consolidada sobre a matéria, mas posicionamentos jurídicos divergentes. Algumas decisões a favor do entendimento sobre a existência de vínculo empregatício foram proferidas no país ${ }^{15}$. No entanto, estas têm sido reformadas em segunda instância, após recursos apresentados pelas empresas de aplicativos, demonstrando o grande desafio para o reconhecimento do direito trabalhista para essa categoria. É importante sublinhar que tais decisões, além de negar reconhecimento do vínculo, não oferecem alternativas de proteção aos trabalhadores, que permanecem à margem de direitos do trabalho.

\section{Relações com as empresas}

Para $44,8 \%$ dos respondentes do questionário, o principal motivo para trabalhar como motorista por aplicativo é esta atividade ser uma alternativa ao desemprego. Tal número pode revelar que este é seu trabalho principal depois que se encontraram em situação de desemprego, e não um "bico" ou complemento de renda, como quer fazer crer a publicidade das empresas-plataforma. Além disso, 48,3\% dos respondentes afirmam reconhecer-se como empreendedores. Este dado também chama a atenção para a representação que os motoristas têm de si mesmos, podendo, de alguma maneira encobrir as relações de subordinação a que estão submetidos, o que é reforçado, por exemplo, pela dubiedade presente no contrato da principal empresa no setor ao afirmar haver uma relação contratual direta, mas que não é nem de controle, nem de gerenciamento.

Em seus Termos e condições gerais dos serviços de tecnologia, a Uber afirma: 
Quadro 1. Legislações sobre transporte individual privado no Brasil e Rio de Janeiro, 2018-2020.

\begin{tabular}{|c|c|c|c|c|}
\hline Ano & Âmbito & Documento & Resumo & Situação \\
\hline 2018 & Federal & $\begin{array}{l}\text { Lei } \mathrm{n}^{\circ} \\
13.640 / 18 \\
\text { (Lei do } \\
\text { Uber) }\end{array}$ & $\begin{array}{l}\text { Altera a Lei de Mobilidade Urbana 12587/12 e determina } \\
\text { que compete exclusivamente aos Municípios e ao Distrito } \\
\text { Federal regulamentar e fiscalizar o serviço de transporte } \\
\text { remunerado privado individual de passageiros }\end{array}$ & Em vigor \\
\hline 2018 & Municipal & $\begin{array}{l}\text { Decreto } \\
44399 / 18\end{array}$ & $\begin{array}{l}\text { Regulamenta o serviço de Transporte Remunerado } \\
\text { Privado Individual de Passageiros, por Aplicativo, no } \\
\text { município do Rio de Janeiro e determina normas para a } \\
\text { circulação na cidade }\end{array}$ & Em vigor \\
\hline 2019 & Federal & $\begin{array}{l}\text { Decreto } \\
9792 / 19\end{array}$ & $\begin{array}{l}\text { Regulamenta a exigência de inscrição de motoristas de } \\
\text { transporte remunerado individual de passageiros no INSS }\end{array}$ & Em vigor \\
\hline 2019 & Municipal & $\begin{array}{l}\text { Decreto } \\
46417 / 19\end{array}$ & $\begin{array}{l}\text { Dispõe sobre demais regras para a atuação dos motoristas } \\
\text { e das empresas no município. Entre essas regras, } \\
\text { permanece vedada ao motorista, antes do embarque do } \\
\text { passageiro, a informação sobre o destino da viagem }\end{array}$ & Em vigor \\
\hline 2019 & Estadual & $\begin{array}{l}\text { Lei } n^{\circ} \\
8552 / 2019\end{array}$ & $\begin{array}{l}\text { Determina que Aplicativos de transporte terão que } \\
\text { disponibilizar SAC (Serviço de Atendimento ao Cliente) } \\
24 \text { horas por dia e amplia o tempo de cancelamento } \\
\text { gratuito da viagem }\end{array}$ & Em vigor \\
\hline 2020 & Federal & $\begin{array}{l}\text { Emenda } \\
n^{\circ} 5,1066 / \\
2020\end{array}$ & $\begin{array}{l}\text { Prevê auxílio emergencial por três meses para os } \\
\text { trabalhadores formais inativos (contrato intermitente) } \\
\text { e informais, no valor de R } \$ 600 \text { (seiscentos reais), } \\
\text { em decorrência da emergência de saúde pública de } \\
\text { importância internacional decorrente do COVID-19 }\end{array}$ & $\begin{array}{l}\text { Transformada em } \\
\text { norma jurídica, } \\
\text { com veto parcial. } \\
\text { Tal veto invalida } \\
\text { a inclusão dos } \\
\text { motoristas por } \\
\text { aplicativo como } \\
\text { beneficiários } \\
\text { do auxílio } \\
\text { emergencial }\end{array}$ \\
\hline
\end{tabular}

Fonte: Criado pelas autoras a partir de documentos legislativos.

Ao concordar com estes Termos, Você cria uma relação contratual direta conosco. No entanto, nós não controlamos ou gerenciamos Você ou os serviços prestados por Você aos Usuários, nem temos o direito de fazê-lo, de forma geral ou durante a realização de Viagens. Os presentes Termos regem tão somente a utilização do nosso Aplicativo de Motorista (p. 3, grifos nossos).

Frente a essa tentativa de apagamento do vínculo de emprego, entendemos com Abílio ${ }^{16}$ que o suposto empreendedorismo se caracterizaria na verdade por um autogerenciamento subordinado destes trabalhadores.

A lógica complexa dos algoritmos - por exemplo, na alocação de corridas, na compilação dos percursos e na estrutura de pagamento - e a falta de transparência sobre captação e uso dos dados produzidos por trabalhadores e consumidores são elementos estruturais para o sistema de controle das empresas-plataforma. Não haver clareza sobre as regras que regem o trabalho, as- sim como sobre como elas funcionam e o que as fundamentam, configura uma assimetria de poder e informação ${ }^{17}$ entre as empresas e os trabalhadores.

Um importante aspecto nessa assimetria é o controle unilateral das informações sobre a demanda e a oferta de trabalhadores, possibilitando às empresas estimular a participação dos considerados por elas "mais produtivos" e punir os que não se adequam aos seus interesses econômicos, mantendo-os permanentemente inseguros $^{7}$. Um exemplo deste estímulo à insegurança passa pela duração da jornada de trabalho, que é pouco previsível, já que depende do valor que se consegue fazer em um dia. No questionário aplicado, para 48,3\% dos respondentes a jornada de trabalho é determinada pelo cumprimento de meta de valor definida pelo próprio motorista. $\mathrm{O}$ valor das corridas e a porcentagem que é retida pelas empresas, por sua vez, sofre variações estabelecidas de forma unilateral por elas, fazendo 
com que muitas vezes sejam realizadas jornadas exaustivas.

Outro exemplo são os desligamentos autocráticos dos motoristas dos aplicativos. Segundo um interlocutor-chave entrevistado (21/10/2020), eles tendem a ser mais comuns entre os motoristas mais antigos, na medida em que já desenvolveram estratégias para evitarem jornadas extenuantes e ainda assim terem um ganho médio satisfatório. Quando questionado sobre como imagina uma relação de trabalho ideal, ele responde que seria uma relação de escolhas. De o motorista poder escolher, por exemplo, os serviços que comporão o cálculo de sua tarifa, assim como as formas de pagamento, porque no momento, segundo o entrevistado, se diz que se pode escolher, mas se um motorista começa a cancelar viagens em dinheiro, provavelmente ele é punido ou até banido por isso. Conclui que uma boa relação seria uma relação com uma interferência menor dos aplicativos, com mais transparência.

Mais um pilar dessa autonomia na subordinação $0^{8}$ é a falta de respostas quando os motoristas sentem necessidade de apoio.

Muita cobrança e nenhum retorno, esse suporte que não te ajuda em nada, as respostas são sempre as mesmas, independente do assunto, você comenta um problema e eles te mandam uma resposta qualquer já pronta, parece que [quem responde] é uma máquina. (Comentário de motorista em página da Associação de Motoristas Particulares Autônomos - AMPA-RJ - no Facebook, maio de 2020)

Esses relatos mostram que apesar do conjunto de normas que são impostas pela empresa, não há um suporte dado pelas prescrições que possa apoiar as infidelidades que aparecem no curso da atividade. Assim, ao procurar um respaldo organizacional que os ajude a sanar os problemas, os motoristas deparam-se com um vazio de normas $^{10}$, contribuindo para uma permanente sensação de insegurança.

Sobre possíveis reservas de alternativas na relação com as empresas, um exemplo que mostra certa pressão do polo da atividade sobre o polo mercantil na quase ausência de intervenção do polo político, é a elaboração pelas associações de motoristas de um projeto para embasar o diálogo com essas empresas no que tange à tarifa, segurança e respeito ao motorista ${ }^{18}$.

\section{Relação com os passageiros}

A avaliação e gestão com base nos indicadores de desempenho a partir de uma métrica de objetivos quantificados e prioridades nos resultados se transformou na principal forma de controle e poder no mundo do trabalho. Um dos diferenciais para a Uber conquistar uma ampla clientela foi, além do preço baixo, a promessa da qualidade no atendimento, sustentada por um sistema de avaliação baseado em um gerenciamento algorítmico. Este sistema é assimétrico e motivo de insatisfação dos motoristas, como se depreende do relato a seguir:

Falta respeito aos "parceiros" pois é ele quem paga o carro, combustivel, manutenção e ainda é obrigado a tolerar falta de educação de passageiros e suas avaliações baixas, sem direito a defesa. Empresa só ouve passageiros e qualquer mentira inventada é aceita. Nós não temos direito a defesa e muito menos a contestação que poderia nos salvar do rebaixamento da pontuação. Chega a ser revoltante (comentário de motorista em postagem da página da AMPA-RJ no Facebook, maio de 2020).

A avaliação da Uber é feita duplamente ao final de cada corrida: pelo passageiro que avalia o motorista com base na experiência da viagem e pelo motorista que avalia o usuário, ambos em uma escala de uma a cinco estrelas. A depender da pontuação alcançada, o sistema de avaliação permite ou não ao motorista o acesso a categorias e benefícios especiais da Uber. A avaliação negativa dos clientes pode levar a punições e até mesmo ao desligamento do motorista no aplicativo.

Para a plataforma, a avaliação dos usuários será fonte de dados sobre a qualidade do serviço realizado. Assim, na uberização, a multidão de consumidores gera informações para o controle e para a avaliação da multidão de trabalhadores $^{16}$. E, seguindo a característica das multidões, as avaliações são anônimas: nem passageiros nem motoristas veem as pontuações dadas por eles a uma viagem ou pessoa específica. Isso provoca descontentamento nos motoristas, que sentem que os clientes não reconhecem seus esforços:

Duas coisas: os passageiros não sabem os valores reais das estrelas e muitos dão nota 3 ou 4 pensando estar dando uma nota boa e não é (de 4 para baixo, todas são exponencialmente negativas). A única nota positiva é a 5 estrelas. E todo passageiro insatisfeito no mínimo que seja sempre avalia e avalia mal, mas nem todos que saem satisfeitos avaliam, sempre discordei desse modelo pela falta de informação (relato de motorista em vídeo no Youtube $)^{19}$.

Os motoristas não têm acesso às regras de como se distribuem as demandas, nem de como são feitas as médias de suas avaliações. O resultado varia da suspensão ao desligamento. $\mathrm{O}$ aviso de possíveis sanções chega via mensagem sem 
direito a defesa. E negar a viagem também pode gerar punição (bloqueio temporário). As sanções já são altas ao se perder uma única estrela:

O que mata é você ter que fazer de 10 a 13 viagens 5 estrelas pra subir um pontinho, aí você pega um pobre de espírito que te dá 4 estrelas e sua nota já cai, acho que falta a Uber conscientizar o passageiro sobre avaliação (relato de motorista em vídeo no Youtube ${ }^{19}$.

Os motoristas são controlados pelos usuários antes mesmo de iniciarem a viagem, pela identificação de sua geolocalização. Cria-se um sistema de vigilância permanente que se retroalimenta pela ação dos trabalhadores e dos clientes ${ }^{4}$. Essa é uma tensão vivenciada pelos motoristas constantemente submetidos ao medo de serem mal avaliados.

Com esse sistema de avaliação pelos clientes, a empresa estabelece o controle e o gerenciamento do processo de trabalho, se utilizando dos resultados das avaliações para classificar os trabalhadores, criando assim um ranqueamento entre eles. Configurando-se, de acordo com Abílio 9 em elemento que será utilizado como critério automatizado na distribuição do trabalho e em determinações da remuneração (p. 43). Assim, esse sistema é estruturante da relação empresa-motorista, estabelecendo um padrão de qualidade que o trabalhador deve seguir, "a partir de regras informalmente definidas” (p.43).

\section{Relações entre motoristas}

Os trabalhadores acabam por criar formas de resistir às tentativas de controle das empresas $e$ dos consumidores sobre o desenvolvimento de sua atividade, reconhecendo que há contradições entre os princípios difundidos pela uberização e a realização efetiva de seu trabalho ${ }^{20}$. Dentre tais tentativas parecem despontar a formação de entidades coletivas relativamente pertinentes ${ }^{10}$, formas mais fluidas de sinergia entre os trabalhadores, que esboçariam resistências, mesmo que de modo não linear e, muitas vezes, ainda alinhadas ao discurso do empreendedorismo.

A formação de associações de motoristas e a comunicação intensa em redes sociais seriam indícios da construção de estratégias coletivas para pressionar a redefinição das normas das empresas. O questionário mostra esta construção: 93\% dos respondentes estão em grupos de WhatsApp, $41,4 \%$ no Facebook, 44,8\% em canais do Youtube e $69 \%$ são filiados a associações. Neste caso, o alto índice, pode ser explicado pelo fato de o instrumento ter sido aplicado em reunião come- morativa de associações de motoristas. Em tais espaços, motoristas compartilham dicas de como obter melhores rendimentos, segurança, notícias sobre a legislação, ou mesmo publicam memes e fazem denúncias. Percebe-se aí, a expressão de redes de sociabilidade ${ }^{21}$ construídas pelos trabalhadores, que atuam como potentes meios de disseminação de informação, possibilitando o apoio e o aprendizado mútuos na realização de trabalhos não regulados, informais.

Outra dimensão desses traços de coletividade são as associações de motoristas. De acordo com os interlocutores-chave, o Rio de Janeiro possui quatro destas: duas na capital, uma em Niterói e uma em Cabo Frio, além de outras em formação. As primeiras surgiram entre 2015 e 2016 durante reação negativa aos motoristas da Uber e também de forte greve dos taxistas no Rio de Janeiro, seguida da deflagração de liminares e legalização municipal nesta cidade. Desde então, buscam reconhecer a profissão, orientar e viabilizar a segurança para o motorista e o cliente, além de algumas atuarem como um "clube de benefícios".

$\mathrm{Na}$ relação entre motoristas há indícios da emergência ainda frágil de uma categoria profissional, ou dos traços de uma entidade coletiva relativamente pertinente ${ }^{10}$. Dialogando com Abílio $^{4,9}$, vemos que as estratégias de coletivização, a partir da formação e reconhecimento de uma categoria profissional (com a "lei do Uber") podem se encaminhar para o desenvolvimento de uma profissionalidade insuspeita em meio ao "trabalho amador": a de motorista (até independente do uso de aplicativos). Poder-se-ia dizer então, que a ideia de um trabalho isolado, que se realiza "sozinho", e a competitividade incentivada pelas empresas-aplicativo, ao reduzirem o valor das corridas com a entrada (sem limites) de novos motoristas, é contraposta, mesmo que por ora ainda timidamente, por esses desenhos de coletivo. De tal maneira que esses indícios de profissionalidade e de um patrimônio de vivências desses trabalhadores pode ser percebido em algumas falas: isso acaba sendo uma profissão, e não um 'bico' ou ainda, todo mundo da nossa categoria vem de outra categoria e traz conhecimentos agregados (Live no Facebook, 17/04/2020).

A tensão entre os polos ergológico, mercantil e político é grande e pode ser exemplificada pela dificuldade de mobilizar coletivamente os motoristas para se manifestar, ao muitas vezes argumentarem que deixarão de ter garantido seu rendimento do dia. Outra tensão entre os polos se manifesta na desconfiança que muitos deles têm em relação à política ou à dimensão dos direitos 
sociais, o que contribuiria, por exemplo, para que ao mesmo tempo em que se queixam de suas condições de trabalho, abram mão de direitos trabalhistas. É o que Grohmann ${ }^{22}$ aponta como lutas pré-figurativas. Ou seja, elas trazem elementos de baixo para cima, embora não estejam isentas de contradições e complexidades, muito relacionadas com a própria realidade brasileira, onde algumas das características da chamada gig economy (uma economia de bicos) não são uma novidade.

\section{O trabalho durante a pandemia}

Se as condições de trabalho desta categoria já vêm sendo esgarçadas desde o início de sua atuação, num contexto de pandemia sua vulnerabilização tem como agravantes a redução da demanda pelo serviço e o risco de contaminação e letalidade. Neste contexto, trabalhadores de transporte, como os motoristas por aplicativos, dentre vários outros substancialmente informais e desprotegidos, neste momento estão sendo considerados prestadores de serviços essenciais para o funcionamento da sociedade ${ }^{23,24}$. Se por um lado, a situação é dramática, paradoxalmente vem contribuindo para que a questão da saúde no trabalho (e dos direitos e condições de trabalho) ganhe visibilidade e atenção da sociedade e dos próprios trabalhadores ${ }^{25}$.

Em março de 2021, no Brasil, a Uber iniciou uma política de assistência financeira por até 14 dias aos motoristas e entregadores parceiros diagnosticados com COVID-19 ou isolados com suspeita. No mês seguinte houve ampliação dos critérios de qualificação, com inclusão de motoristas e entregadores parceiros com problemas de saúde preexistentes ${ }^{6}$. No entanto, apesar da proposta de divisão de prejuizos garantida pela empresa até o dia 8 de junho de 2020, o cálculo da assistência financeira tem como base a média semanal de ganhos do motorista nos últimos três meses, a partir da data de solicitação do auxílio. Se considerarmos que as consequências econômicas devido à pandemia vêm se agravando desde o mês de março, o trabalhador encontra-se em clara desvantagem.

Nota técnica da CONAFRET/MPT 01/2020 apresentou recomendações para conter a disseminação do novo coronavírus voltadas às empresas de transporte por plataformas digitais ${ }^{26}$. A nota recomenda que sejam garantidas aos trabalhadores informações e orientações a respeito das medidas de controle, bem como condições sanitárias, protetivas, sociais e trabalhistas, para que se reduza ao máximo o risco de contaminação durante o exercício de suas atividades profissionais. Já aqui se observa o descumprimento da recomendação pela ausência de condições protetivas nos veículos, além da desproteção social e trabalhista. Por fim, é imperativo destacar o que está previsto no item $\mathrm{n}^{\circ} 8$ :

ASSEGURAR que, na hipótese de determinação oficial, por parte dos órgãos públicos competentes, de restrição de circulação pública de pessoas, que afetem as atividades profissionais desempenhadas no transporte de passageiros e transporte de mercadorias, por plataformas digitais, a prestação dos serviços será paralisada ${ }^{27}$.

$\mathrm{O}$ isolamento social implicou na restrição de circulação pública de pessoas e o serviço continuou sendo oferecido sem que a paralisação remunerada tenha sido oferecida à categoria, o que afetou diretamente suas atividades profissionais e meio de sobrevivência.

Diante da insuficiência de políticas públicas ou apoio das empresas, observamos que os motoristas têm se articulado nas redes sociais para criar e compartilhar estratégias de proteção à saúde e sobrevivência financeira diante da diminuição na demanda por viagens.

\section{Considerações finais}

As análises trazidas aqui foram construídas a partir de um exercício inspirado no espaço tripolar ergológico. Elas compõem uma espécie de caleidoscópio de impressões, reflexões e afetos com os quais entramos em contato ao nos aproximar com um olhar de pesquisa de uma realidade tão candente para quem vive hoje em centros urbanos. Revela-se, dentre outras coisas, a materialização de processos históricos - particularmente no Brasil - de precarização e transformações do trabalho na consolidação de um trabalhador just-in-time .

A leitura de Supiot ${ }^{8}$, Carelli ${ }^{7}$ e Abílio ${ }^{9}$ ressalta a ambiguidade presente na ideia sedutora de ser seu próprio patrão e a impossibilidade de emancipação na prática, revelando-se uma autonomia imediatamente negada pelo dever de aliança, e não parceria de fato - uma parceria assimétrica. Se, como aponta Linhart ${ }^{27}$, o que é almejável no trabalho não é a subordinação e sim uma real autonomia, buscar sua conquista torna-se um verdadeiro encargo. E essa conquista passa pelo debate no polo do político sobre a assimetria de poder em que têm se dado processos de trabalho operados por essas empresas-plataforma. Por trás da suposta e enaltecida objetividade e neutralida- 
de, destaca-se a opacidade em que se estabelecem os mecanismos decisórios a elas subjacentes ${ }^{3}$.

É neste sentido que entendemos a luta pela saúde, como caminho que permita constituir espaços de vida e trabalho, tendo a construção do comum como desafio e amparo para a liberdade e emancipação. Em suma, a ideia seria não contrapor a evolução tecnológica à evolução de nosso senso de humanidade e de coletividade, apostando, por exemplo, em um trabalho codeterminado, em que trabalhadores estariam en- volvidos desde o momento da programação da plataforma até seu uso ${ }^{28,29}$. É imperativo lembrar que nenhuma ação que vise recriar nosso mundo e garantir a conciliação entre saúde, trabalho e direitos conseguirá avançar se não pudermos contar com uma dinâmica frutífera, e tendencialmente equilibrada, entre os três polos mencionados. Assim, para que o polo da atividade possa ter a visibilidade e emergência que deveria, o polo do político, da politea, precisa de fato atuar como protetor frente às imposições do polo mercantil.

\section{Colaboradores}

Todas as autoras têm participado ativamente do projeto, seja como pesquisadoras profissionais, seja como estudantes de graduação e pós-graduação em formação. $\mathrm{Na}$ formulação do artigo todas contribuíram de maneira importante e consistente, tanto na definição de seu escopo, como na organização e discussão dos resultados e na revisão e aprovação de sua versão final.

\section{Referências}

1. Slee T. Uberização: a nova onda do trabalho precarizado. São Paulo: Elefante; 2017.

2. Kramer J. A Economia compartilhada e a Uberização do Trabalho: utopias do nosso tempo? [dissertação]. Paraná: Universidade Federal do Paraná; 2017.

3. Casilli A. Existe una cultura laboral digital global? Marginacíondeltrabajo, desigualdades globales Y colonialidade. In: Trabajo, conocimento y vigilância: 5 ensayos sobre tecnologia. AGETIC. La Paz: Bolívia; 2018.

4. Abílio L. Uberização: a era do trabalhador just-in-time? Estudos Avançados 2020; 34(98).

5. Melek MI, Boskovic AB. A revolução digital e o infoproletário no Brasil. Jornal do Congresso Brasileiro do Trabalho [Internet]. 2019 [acessado em 2020 maio 19]; 59:1-9. Disponível em: http://www.ltr.com.br/ congressos/jornal/direito/jornal_direito.pdf\#page $=9$.

6. Fatos e Dados sobre a Uber [internet]. Uber; $2020 \mathrm{fev}$ 18. [acessado 2020 jun 28] Disponível em: https:// www.uber.com/pt-BR/newsroom/fatos-e-dados-sobre-uber/

7. Carelli R. O Caso Uber e o controle por programação: de carona para o Século XIX. In: Paes Leme AC, Rodrigues B, Chaves Júnior JE, coordenadores. Tecnologias Disruptivas e a Exploração do Trabalho Humano. São Paulo: LTR; 2017. p. 130-146

8. Supiot A. La gouvernance par les nombres. Paris: Fayard; 2015.

9. Schwartz Y. O homem, o mercado e a cidade. In: Schwartz Y, Durrive L, organizadores. Trabalho e Ergologia: conversas sobre a atividade humana. Niterói: EDUFF; 2010. p. 247-273. 
10. Schwartz Y, Durrive L, organizadores. Trabalho e ergologia: conversas sobre a atividade humana. Tradução de Jussara Brito e Milton Athayde. Niterói: EdUFF; 2010.

11. Fontes V. Capitalismo em tempo de uberização: do emprego ao trabalho. Marx e o Marxismo 2017; 5(8):45-67.

12. Durrive L, Schwartz Y. Glossário da ergologia. Laboreal [revista eletrônica], 2008 Jul 01 [acessado 2020 maio 26]; 4(1). Disponível em: http://journals.openedition.org/laboreal/11665

13. Canguilhem G. Meio e normas do homem no trabalho. Pro-posições 2001; 12(2-3):109-121

14. Brasil. Lei 13.640, de 26 de março se 2018, Altera a Lei $\mathrm{n}^{\mathrm{o}}$ 12.587, de 3 de janeiro de 2012, para regulamentar o transporte remunerado privado individual de passageiro. Brasília; 26 de março de 2018.

15. Frazão A. A Decisão do Reino Unido sobre Motoristas da Uber: o que temos a aprender com ela? In: Leme ACRP, Rodrigues BA, Chaves Junior JER, organizadores. Tecnologias Disruptivas e a Exploração do Trabalho Humano, São Paulo: LTr; 2017. p. 318-322

16. Abílio L. Uberização: Do empreendedorismo para o autogerenciamento subordinado. Rev Psicoperspectivas 2019; 18(3):41-51.

17. Rosenblat A, Stark L. Algorithmic Labor and Information Asymmetries: A Case Study of Uber's Drivers. Intern J Commun 2016; 10: 3758-3784.

18. Moura D. Proposta de Projeto Público Tarifas, segurança e respeito com motoristas por aplicativos - VERSÃO 4.0; 2020.

19. UBER. Cuidado ao Avaliar os Passageiros [Youtube vídeo]. 2018 mar 15 [acessado 2020 jun 28]. Disponível em: https://www.youtube.com/watch?v=zRCC9GJe6YA

20. Rebechi C. Prescrições da gestão do trabalho uberizado: "debate de normas" entre formas de controle e de resistência. $41^{\circ}$ Congresso Brasileiro de Ciências da Comunicação. Joinville; 2018; Set 2-8.

21. Sato L. Diferentes faces do trabalho no contexto urbano. In: Coutinho MC, Bernardo MH, Sato L, organizadores. Psicologia Social do Trabalho. $1^{\text {aed. Petrópo- }}$ lis: Vozes; 2017, v. 1. p. 151-174.

22. Grohmann R. In: Vida acima do lucro - A luta dos trabalhadores das plataformas em contexto da pandemia [Youtube vídeo]. Grupo de Pesquisa Trabalho e Práxis: UFES: 2020 [acessado 2020 jun 28] Disponível em: https://www.youtube.com/watch?v=GAossJy-lI8

23. International Labor Organization. ILO Monitor: $\mathrm{CO}$ VID-19 and the world of work. $2^{\text {a }}$ ed. Updated estimates and analysis [Internet], 07 Abr 2020 [acessado 2020 Maio 13]. Disponível em: https://www.ilo.org/ wcmsp5/groups/public/@dgreports/@dcomm/documents/briefingnote/wcms_740877.pdf.
24. Amorim H, Moda F. O coronavírus, os entregadores e o futuro do trabalho no Brasil. Instituto Humanitas Unisinos [revista eletrônica]. 2020 Abr 22 [acessado 2020 jun 11]. Disponível em: http://www.ihu.unisinos.br/598243

25. If platforms do not protect gig workers, who will? New Internationalist [revista eletrônica]; $2020 \mathrm{Apr}$ 23 [acessado 2020 maio 13] Disponível em: https:// newint.org/features/2020/04/23/if-platforms-do-not-protect-gig-workers-who-will

26. Brasil. Ministério Público do Trabalho (MPT) Nota Técnica CONAFRET 01/2020. Nota Técnica para orientação da atuação do Ministério Público do Trabalho em face das medidas governamentais de contenção da pandemia da doença infecciosa COVID 19, voltada às empresas de transporte de mercadorias $\mathrm{e}$ de transporte de passageiros, por plataformas digitais [Internet]. Brasília: MPT; 2020. [acessado 2020 maio 04]. Disponível em: http://www.saude.mppr.mp.br/ arquivos/File/Corona/atos_MPT/NT_conafret.pdf

27. Linhart D. A uberização do trabalho não é inevitável. Um assalariado sem submissão é possível. Le Monde Diplomatique Brasil 2017. Edição 120, setembro 6.

28. Scholz T. Cooperativismo de plataforma: contestando a economia do compartilhamento corporativa. São Paulo: Fundação Rosa Luxemburgo; 2016.

29. Chaumon ME. Du rôledes TIC danslatransformationdigitale de l'activité et de lasantéautravail. $\mathrm{La} R e$ vue des conditions de travail; n. 6, setembre 2017.

Artigo apresentado em 30/06/2020

Aprovado em 16/07/2021

Versão final apresentada em 18/07/2021

Editores-chefes: Romeu Gomes, Antônio Augusto Moura da Silva 